\title{
Extent of the frontal sinuses in the aspect of neurosurgical craniotomy approaches
}

\author{
Z. Siedlecki1, M. Sabramowicz², J. Woźniak1, M. Śniegocki', K. Nowak¹, M. Baumgart², \\ E. Główczewska-Siedlecka³ ${ }^{3}$ M. Szpinda², M. Wiśniewski²
}

'Department of Neurosurgery, Neurotraumatology and Paediatric Neurosurgery, the Ludwik Rydygier Collegium Medicum in Bydgoszcz, the Nicolaus Copernicus University in Torun, Poland

2Department of Normal Anatomy, the Ludwik Rydygier Collegium Medicum in Bydgoszcz, the Nicolaus Copernicus University in Torun, Poland

${ }^{3}$ Department of Geriatrics, the Ludwik Rydygier Collegium Medicum in Bydgoszcz, the Nicolaus Copernicus University in Torun, Poland

[Received: 28 September 2021; Accepted: 27 October 2021; Early publication date: 5 November 2021]

\begin{abstract}
Background: Frontal sinuses within the frontal bone can be a potential obstacle in neurosurgical approach in this region. Their unintended opening during craniotomy is not beneficial due to the risk of brain infections by bacteria inhabiting the sinus mucosa. Therefore, such opening should be avoided whenever the surgical procedure does not involve the sinus itself. The aim of the study was the morphometric analysis of the frontal sinuses based on computed tomography imaging. Materials and methods: The width, height, projection surface area and location of the highest and most lateral points of the sinuses were determined.

Results: The vertical diameter of the sinuses was found to be greater in men compared with women. The most lateral point of the sinuses was located higher in men, and in men was located higher on the left side. The results obtained may indicate that the frontal sinuses tend to be larger in men and that air cells in men extend further in the upper-lateral direction on the left side of the frontal bone. Conclusions: This may cause an increased risk of unintentional opening of the left frontal sinus during frontal craniotomy or pterional craniotomy with frontal extension. (Folia Morphol 2022; 81, 4: 1047-1053)
\end{abstract}

Key words: frontal sinuses, craniotomy, neurosurgical approach

\section{INTRODUCTION}

The frontal sinuses are air cavities within the frontal bone. They are lined with mucosa and joined with the nasal cavity [10]. They are characterised by large variations in size: from aplastic to highly developed and multi-chamber [8]. Infections located in the frontal sinuses may be complicated by brain infection [3]. In neurosurgical procedures not directed at the frontal sinuses, opening of the latter should be avoided [1], given the risk of potential infectious complications. Among the intracranial pathologies in which neurosurgical access does not require opening the frontal sinuses are most frontal lobe tumours (Fig. 1), aneurysms of the anterior cerebral artery and the anterior communicating artery, operated using a frontal interhemispheric approach [5]. When performing frontal craniotomy, it is important to know how far upward and laterally the sinuses in the frontal bone

Address for correspondence: Dr. med. Z. Siedlecki, Department of Neurosurgery, Neurotraumatology and Paediatric Neurosurgery, the Ludwik Rydygier Collegium Medicum in Bydgoszcz, ul. Skłodowskiej-Curie 9, 85-094 Bydgoszcz, Poland, tel: +48 606302680 , e-mail: siedlecki@cm.umk.pl

This article is available in open access under Creative Common Attribution-Non-Commercial-No Derivatives 4.0 International (CC BY-NC-ND 4.0) license, allowing to download articles and share them with others as long as they credit the authors and the publisher, but without permission to change them in any way or use them commercially. 


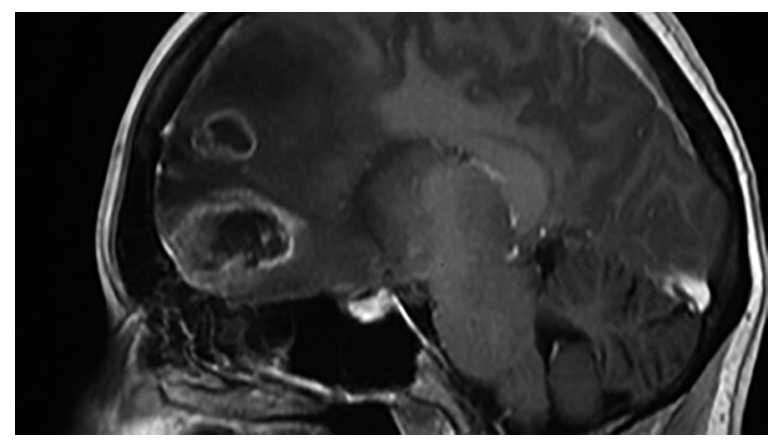

Figure 1. Magnetic resonance imaging showing a high-grade glioma located posteriorly of the frontal sinus.

extend, and it was our aim in this study to determine these diameters.

\section{MATERIALS AND METHODS}

The study consisted of a retrospective analysis of computed tomography (CT) scans from 120 people (60 men, 60 women). The analysed scans were obtained from patients of the Department of Neurosurgery, Collegium Medicum, Nicolaus Copernicus University. The patients were treated due to various conditions constituting indications for a CT examination: brain tumours, intracranial haemorrhages, hydrocephalus, brain injuries. The analysis did not include CT images of patients with skull fractures and following neurosurgical or laryngology procedures which involved the frontal sinuses and, therefore, could lead to changes in the patients' anatomical conditions. The patients were treated in 2018-2019, and the retrospective analysis was conducted in 2020.
The study received approval from the Bioethics Committee of the Ludwik Rydygier Collegium Medicum in Bydgoszcz, the Nicolaus Copernicus University in Torun (document no. KB 35/2020). The analysed CT scans were acquired from 60 women aged 18-78 years (mean age: 56.43 ) and 60 men aged $18-80$ years (mean age: 54.35 ), using the Discovery CT 750 HD GE scanner in the Digital Imaging and Communications in Medicine (DICOM) format. The scans were performed at a step of $0.4 \mathrm{~mm}$. Bone scans were used for measurements.

The frontal sinuses (right and left) were measured based on transverse and frontal scans as shown in Figure 2.

The measurements included:

- the greatest transverse diameter (width) measured in the transverse plane between the midline and the most lateral point of the sinus on each side (Fig. 2A, measurement 1);

- the greatest vertical diameter (height) measured in the frontal plane between the line defined by the supraorbital margins and the highest point of the frontal sinus on each side (Fig. 2B, measurement 2);

- the distance between the highest point of the sinus and the midline, measured in the frontal plane on each side (Fig. 2B, measurement 3);

- the distance between the most lateral point of the sinus and a line defined by the supraorbital margins, measured in the frontal plane on each side (height of the most lateral point) (Fig. 2B, measurement 4);

- sinus projection surface area, calculated based on the contour of the sinus using Osirix 3.9 MD.

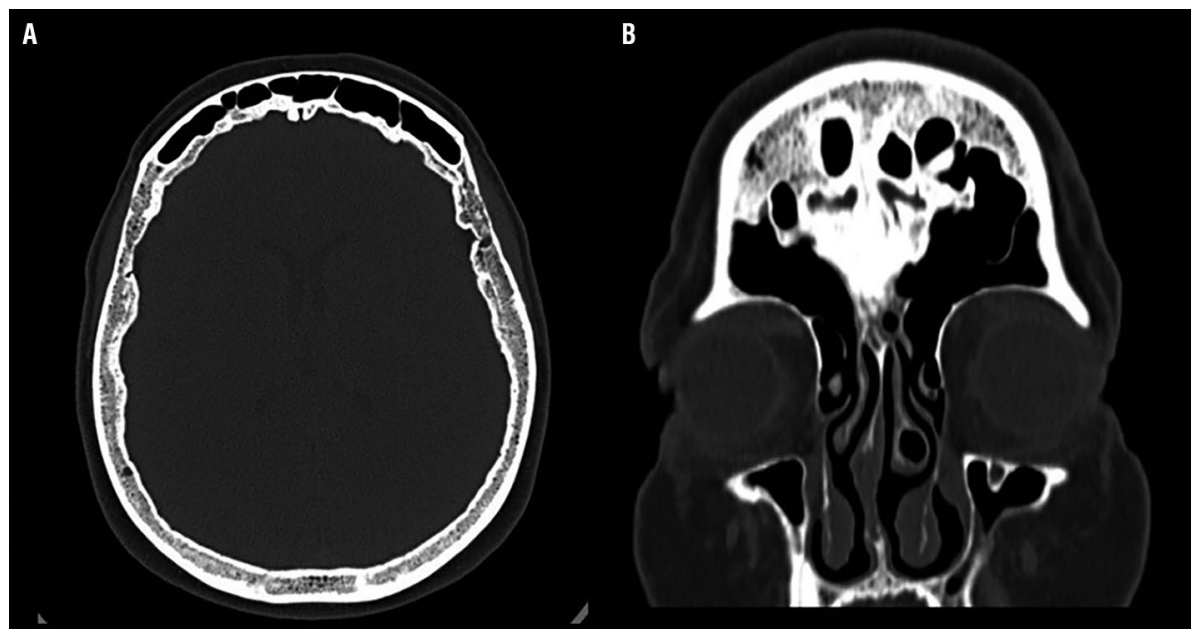

Figure 2. Sample computed tomography scan for frontal sinus measurements; A. Transverse; B. Frontal. 
Table 1. Values of the frontal sinus parameters measured in each sex on the right and left side

\begin{tabular}{|c|c|c|c|c|}
\hline \multirow[t]{2}{*}{ Parameter studied } & \multicolumn{2}{|c|}{ Men } & \multicolumn{2}{|c|}{ Women } \\
\hline & Right & Left & Right & Left \\
\hline Greatest transverse diameter [mm] & $25.10 \pm 2.18$ & $25.30 \pm 2.34$ & $24.40 \pm 2.27$ & $24.30 \pm 2.46$ \\
\hline Greatest vertical diameter $[\mathrm{mm}]$ & $24.70 \pm 2.43$ & $24.50 \pm 2.21$ & $23.70 \pm 2.42$ & $23.80 \pm 2.40$ \\
\hline Diameter: midline - highest point [mm] & $3.20 \pm 0.11$ & $2.40 \pm 0.09$ & $2.20 \pm 0.09$ & $2.30 \pm 0.10$ \\
\hline Height of the most lateral point [mm] & $13.10 \pm 0.12$ & $13.50 \pm 0.11$ & $12.70 \pm 0.10$ & $12.80 \pm 0.09$ \\
\hline Projection surface area $\left[\mathrm{cm}^{2}\right]$ & $6.27 \pm 1.43$ & $6.25 \pm 1.21$ & $6.17 \pm 1.42$ & $6.18 \pm 1.40$ \\
\hline
\end{tabular}

The projection surface area was determined in the frontal projection (Fig. 2B, measurement 5).

The above measurements aligned with the study aim to determine how far upward and laterally the frontal sinuses extend, which is important for a neurosurgeon conducting frontal craniotomy. In this study, no measurements of the parameters examined were performed in the sagittal plane because no benefits of this projection for a neurosurgeon could be found in planning operative approach in order to avoid unintended opening of the sinus.

The results of the investigation were statistically analysed. Distribution of variables was checked using the Shapiro-Wilk (W) test. The homogeneity of variance was checked using Fisher's test. The results were expressed as arithmetic means with standard deviations (SD). To compare the means, Student's t-test for independent variables and one-way analysis of variance were used. Tukey's test was used for post hoc analysis. If no similarity of variance occurred, the non-parametric Kruskal-Wallis test was used. The characterisation of developmental dynamics of the analysed parameters was based on linear and curvilinear regression analysis. The match between the numerical data and computed regression curves was evaluated based on the coefficient of determination $\left(R^{2}\right)$. Correlations between the variables were also determined using Pearson's linear correlation coefficient ( $r$ ).

The parameters studied were compared by sex (female vs. male), and the possible laterality differences (right vs. left) were assessed for each sex separately.

\section{Ethics approval and consent to participate}

The experiment was approved by the Bioethics Committee of the Ludwik Rydygier Collegium Medicum in Bydgoszcz (KB 35/2020). Written informed consent was obtained from the patients for publication of this case report and any accompanying
Table 2. Intra-class correlation coefficients (ICC) values for inter-observer recurrence

\begin{tabular}{lc}
\hline Parameter studied & ICC \\
\hline Greatest transverse diameter & $0.996^{*}$ \\
Greatest vertical diameter & $0.995^{*}$ \\
Diameter: midline - highest point & $0.997^{*}$ \\
Height of the most lateral & $0.998^{*}$ \\
Projection surface area & $0.998^{*}$ \\
\hline
\end{tabular}

${ }^{*}$ Intra-class correlation coefficients marked with asterisk are statistically significant at $p<0.0001$

images. A copy of the written consent is available for review by the Editor of this journal.

\section{RESULTS}

The results obtained for the five parameters measured are summarised in Table 1.

In an attempt to minimise measurement and observer bias, all measurements were completed by one experienced researcher (Z.S.) specialising in image interpretation. Each measurement was reiterated three times under the same conditions but at different times, and then averaged. As shown in Table 2, the intra-class correlation coefficients calculated on the basis of an observer were statistically significant and of excellent reproducibility.

The greatest transverse diameter of the sinuses was $25.1 \pm 2.18 \mathrm{~mm}$ on the right side and $25.3 \pm$ $\pm 2.34 \mathrm{~mm}$ on the left side in men, and $24.4 \pm$ $\pm 2.27 \mathrm{~mm}$ on the right side and $24.3 \pm 2.46 \mathrm{~mm}$ on the left side in women. For the transverse diameter of the sinus assessed in plane, neither sex nor laterality differences were found.

The greatest vertical diameter of the sinuses was $24.7 \pm 2.43 \mathrm{~mm}$ on the right side and $24.5 \pm 2.21 \mathrm{~mm}$ on the left side. In women, the greatest vertical diameter was $23.7 \pm 2.42 \mathrm{~mm}$ on the right side and $23.8 \pm 2.40 \mathrm{~mm}$ on the left side. The vertical diam- 


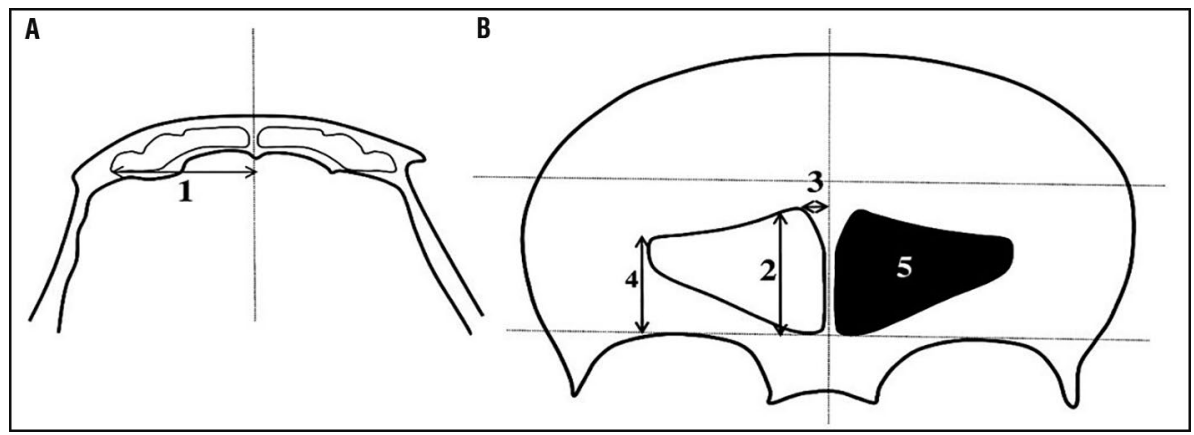

Figure 3. Diagram of measurements; A. Transverse projection; 1 - transverse diameter of the sinus; B. Frontal view; $2-$ vertical diameter of the sinus; 3 - distance between the highest point and the midline; 4 - height of the most lateral point of the sinus; 5 - projection surface area.

eter of the sinuses was greater $(p<0.05)$ in men compared with women (Fig. 2), and no laterality differences were found in either sex.

The distance between the highest point of the sinus and the midline in men was $3.2 \pm 0.11 \mathrm{~mm}$ on the right side and $2.4 \pm 0.09 \mathrm{~mm}$ on the left side. In women, that distance was $2.2 \pm 0.09 \mathrm{~mm}$ on the right side and $2.3 \pm 0.10 \mathrm{~mm}$ on the left side. The distance between the highest points of the frontal sinuses and the midline did not show any sex or laterality differences.

The most lateral points of the frontal sinus in men were $13.1 \pm 0.12 \mathrm{~mm}$ and $13.5 \pm 0.11 \mathrm{~mm}$ above the supraorbital margin on the right and left side, respectively. In women, these points were $12.7 \pm$ $\pm 0.10 \mathrm{~mm}$ and $12.8 \pm 0.09 \mathrm{~mm}$ above the supraorbital margin on the right and left side, respectively. The height of the most lateral points of the frontal sinuses in relation to the supraorbital margins was greater in men, and of the two points in men, that on the left side was located higher than that on the right side (Fig. 3). There were no laterality differences in women.

Projection surface area in men was $6.27 \pm 1.43 \mathrm{~cm}^{2}$ on the right side and $6.25 \pm 1.21 \mathrm{~cm}^{2}$ on the left side. In women, projection surface area was $6.17 \pm$ $\pm 1.42 \mathrm{~cm}^{2}$ on the right side and $6.18 \pm 1.40 \mathrm{~cm}^{2}$ on the left side.

Statistically significant results in reference to sex and side are presented in Table 3.

\section{DISCUSSION}

From a neurosurgeon's point of view, it is important to know how far upward and laterally the frontal sinuses extend. It is because these diameters indicate the likelihood of opening the sinus during neurosurgical procedure. We reviewed the literature on the
Table 3. Statistically significant $(p<0.05)$ difference between parameters measured

\begin{tabular}{lcc}
\hline Parameters measured & $\begin{array}{c}\text { Differences } \\
\text { between sexes }\end{array}$ & $\begin{array}{c}\text { Laterality } \\
\text { differences }\end{array}$ \\
\hline $\begin{array}{l}\text { Greatest vertical diameter } \\
\text { Height of the most lateral point }\end{array}$ & $\begin{array}{c}\text { Male }>\text { Female } \\
\text { Male }>\text { Female }\end{array}$ & $\begin{array}{c}\text { Left }>\text { Right } \\
\text { (in men) }\end{array}$ \\
\hline
\end{tabular}

morphometry of the frontal sinuses. Six references from 2002 to 2019 assessing the morphometry of the frontal sinuses and the diagnostic suitability of $\mathrm{CT}$, and describing clinical implications pertaining to surgical procedures, were found. These references are discussed below in chronological order (Figs. 4, 5).

Kew et al. (2002) [7] analysed the frontal sinuses based on sagittal, frontal and three-dimensional CT scans. Their study methodology partly resembled our study, but they considered the morphology of the frontal sinus in relation to laryngology procedures, not neurosurgery. In general, Kew et al. [7] demonstrated the benefits of assessing sagittal scans in establishing surgical access. The sagittal projection was much better than frontal scans in identifying and assessing the size of the frontal sinus opening. According to Kew et al. [7], the surgical procedure plan was changed based on additional information obtained from sagittal scans in $55 \%$ of cases. However, they did not show any significant difference between the morphology of the frontoethmoidal cells shown in the sagittal and frontal projections [7]. Still, the results obtained by Kew et al. [7] demonstrate the importance of sagittal scans in surgical planning.

Fatu et al. (2006) [4] studied the development of the frontal sinus and its variability throughout human life. It assessed the morphology of the frontal sinus 


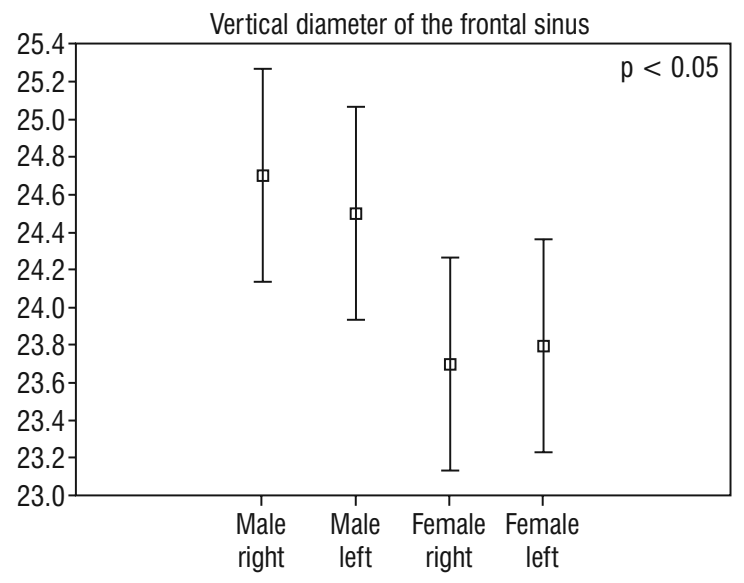

Figure 4. Box plot showing statistically significant differences in sinus height; Male $>$ Female.

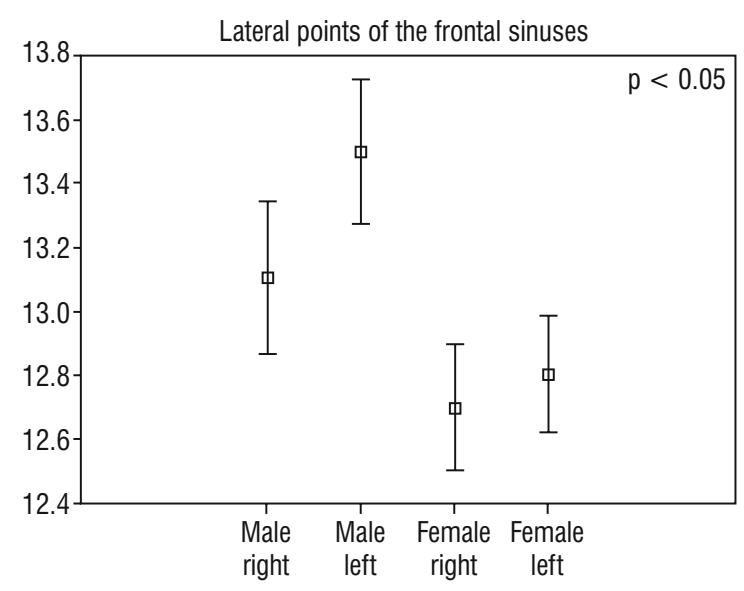

Figure 5. Box plot showing statistically significant differences in the height of the most lateral point of the sinus; Male $>$ Female, Left $>$ Right in men.

using 60 frontal X-ray images of patients of different ages and both sexes [4]. The authors measured the frontal sinus projection surface area in the frontal plane. They used professional software called Bersoft Image 4.02 [4] to measure the surface area of the right and left frontal sinuses in X-ray images. Therefore, the approach in the study by Fatu et al. [4] was similar to our methodology, except for the use of X-ray images instead of frontal CT used in our study. Fatu et al. [4] estimated that the frontal sinus was already visible in 4-year-old children. In $5 \%$ of cases, one-sided or complete absence of the sinus was determined [4]. According to Fatu et al. [4], the frontal sinus projection surface area in the frontal plane increases up to the age of 19 years in synchrony with the overall growth of the splanchnocranium. The authors also pointed out that individual differences in the size and shape of the sinuses in adults depended on environmental factors [4]. In terms of surgical procedures (which was common with the idea behind our study), Fatu et al. [4] noted that bone resorption leading to enlargement of the frontal sinus could potentially complicate surgical procedures conducted in this region in older patients.

Tatlisumak et al. (2008) [11] assessed the diameters of the frontal sinuses in relation to surgical procedures, as in our work. They found that the diameters of the left frontal sinus were usually greater than those of the right frontal sinus, and the sinuses were larger in men than in women. Tatlisumak et al. [11] demonstrated a significant difference in the anterior-posterior diameter between the left and right side in both sexes and showed differences in the height of the left and right sinuses in men and in the width of the right and left sinuses in women. In every case, the diameters on the left side were greater [11]. In both sexes, the highest values of measurements were usually observed in the age group of 31-40 years, and there was a tendency to decrease with age [11]. The authors pointed out that the larger diameter of the left frontal sinus may put it at a greater risk of opening during a surgical intervention [11], which supports the conclusions of our study. In both our study and that by Tatlisumak et al. [11], it was shown that some of the parameters measured were greater in men, while the most lateral point of the sinus in men was located higher on the left side. This suggests that a greater extension of the sinus air cells should be expected on the left side, which may have significant implications for a neurosurgeon performing craniotomy.

Lee et al. (2010) [9] conducted morphometric measurements of the frontal sinuses based on CT in 150 people. CT scans in this study focused on the maxillofacial region, as opposed to craniocerebral CT used in our study owing to the availability of neurosurgical documentation. Lee et al. [9] conducted morphometric measurements in the midline and at a distance of 10,20 and $30 \mathrm{~mm}$ laterally from the midline on both sides. The authors used sagittal, frontal and transverse scans which, except for the sagittal images, is in line with the methodology in our study. They analysed the obtained data for significant differences between measurements taken at selected points of the frontal sinus, focusing on variability depending on the side (left vs. right) and sex. The 
height of the frontal sinus was the greatest in the midline (mean $24.5 \mathrm{~mm}$ ) and gradually decreased toward the sides [9]. The mean width at the level of the supraorbital process was $52.2 \mathrm{~mm}$ [9]. No significant variability between left and right was observed in any measurement. As regards sex differences, Lee et al. [9] stated that men have greater diameters in most of the frontal sinus measurements, but these differences were significant only in or near the midline, and no differences were noted on the sides. In our work, the height of the sinus was the greatest perimedially, only a few millimetres away from the midline. In contrast to Lee et al. [9], however, we did not demonstrate that the height was the greatest in the midline. This was due to the presence of bone septa in the midline.

Guerram et al. (2014) [6] classified the frontal sinuses into four categories: (1) aplastic, (2) hypoplastic, (3) of average size, (4) hyperplastic [6]. This classification is based on a simple quantitative morphological assessment of the sinus size. It has been used by other researchers and has become clinically relevant in assessing the risk of sinus injury (Buller et al., 2019 [2]). Guerram et al. [6] referred the size of the frontal sinuses to the presence of persistent frontal suture. They examined 143 dry human skulls of adult individuals, including 80 skulls with a complete frontal bone fusion and absent frontal suture, as well as 63 skulls with persistent frontal suture [6]. The authors found a statistically significant difference in the size of the frontal sinuses between the two groups of skulls [6]. Aplastic and hypoplastic sinuses were much more frequent in skulls with persistent frontal suture compared with those completely fused ( $57.9 \%$ vs. $11.9 \%$ ), with hypoplastic sinuses being much more frequent (50.8\% vs. $9.4 \%$ ) and aplastic sinuses only slightly more frequent ( $7.1 \%$ vs. $2.5 \%$ ) between the two skull groups [6]. Although in our study we did not consider the presence of persistent frontal suture in the frontal bone, the classification by Guerram et al. [6] may be useful in assessing the size of the frontal sinus in relation to neurosurgical approach.

Buller et al. (2019) [2] determined the size of the frontal sinuses in patients with concave fractures of the sinus anterior wall due to trauma. Their study is related to our analysis, because frontal injuries are a subject of interest of neurosurgery, while unintended penetration of the sinuses during craniotomy can be compared to a trauma. Buller et al. [2] conducted a retrospective study in a group of patients with
Table 4. Review of the literature on the size of the frontal sinuses considering laterality and sex differences

\begin{tabular}{lcc}
\hline Study & $\begin{array}{c}\text { Laterality } \\
\text { differences }\end{array}$ & $\begin{array}{c}\text { Differences } \\
\text { between sexes }\end{array}$ \\
\hline Tatlisumak et al., 2008 [11] & Left $>$ Right & Male $>$ Female \\
Lee et al., 2010 [9] & $\begin{array}{c}\text { Not statistically } \\
\text { significant }\end{array}$ & Male $>$ Female \\
& Left $>$ Right* & Male $>$ Female** \\
$\begin{array}{l}\text { Siedlecki et al., 2021 } \\
\text { (current study) }\end{array}$ & & \\
\hline
\end{tabular}

*In men, the most lateral point of the sinus was located higher on the left side, which may indicate that the left side of the frontal squama tends to fill more extensively with air cells

**For the vertical diameter and the height of the most lateral point

displaced fractures of the anterior part of the frontal sinus. The control group was randomly selected from patients with blunt frontal injuries without fractures. The authors used the Guerram et al. [6] classification of the sinus size into four groups as determined by CT. Buller et al. [2] studied 47 sinuses in patients with fractures and 93 controls. Hyperplasia in the group of patients had an odds ratio of $46: 1(p<0.001)$ compared with the control group [2]. The mean width of the sinus was $73 \mathrm{~mm}$ vs. $46 \mathrm{~mm}(\mathrm{p}<0.001)$, while the mean height was $30 \mathrm{~mm}$ vs. $15 \mathrm{~mm}(p<0.001)$ [2]. In general, the frontal sinuses were larger in the patient group compared with the control group. The authors showed that post-traumatic concave fractures of the anterior wall of the frontal sinus were specific to patients with enlarged sinuses and that increased sinus size predisposed them to such an injury [2]. The idea and methodology of the Buller et al. [2] study was related to our study. If unintended opening of the frontal sinus during neurosurgical approach is treated as a surgical trauma, it is facilitated by the size of the sinus, which was the assumption and basis for our analysis.

Of the literature items presented, two (Tatlisumak et al., 2008 [11]; Lee et al., 2010 [9]) identified differences between the left and right sides and sex differences, similarly to our study. The results are reported collectively in Table 4.

\section{CONCLUSIONS}

Of the five parameters examined, two of them: vertical diameter and the height of the most lateral point were greater in men compared with women. Moreover, in men, the most lateral point of the sinus was located higher on the left compared with the right. This suggests a trend toward larger frontal 
sinuses and a greater extension of air cells in the upper-lateral direction on the left side of the frontal bone in men. Therefore, it may be of help for clinicians to consider that, particularly in men, left-side craniotomy poses a greater risk of opening the frontal sinus compared with that on the right side if the procedure is extended in the frontal direction.

\section{Acknowledgements}

The authors thank the computed tomography technicians and doctors of the Radiology Department for dedicating their skills and professionalism to the acquisition and analysis of images.

\section{Funding}

The study was financed from own funds of the Neurosurgery Department and the Anatomy Department of the Ludwik Rydygier Collegium Medicum in Bydgoszcz. The authors received no specific funding for this work.

\section{Conflict of interest: None declared}

\section{REFERENCES}

1. Başal $Y$, Başak S, Bedrosian JC. Surgical Anatomy of the Paranasal Sinuses. In All Around the Nose. Springer, Cham 2020: 49-55.

2. Buller J, Kreppel M, Maus $V$, et al. Risk of frontal sinus anterior table fractures after craniofacial trauma and the role of anatomic variations in frontal sinus size: A retrospective case-control study. J Craniomaxillofac Surg. 2019; 47(4): 611-615, doi: 10.1016/j.jcms.2019.01.018, indexed in Pubmed: 30718214.
3. Duque CS, Casiano RR. Surgical anatomy and embryology of the frontal sinus. In The frontal sinus. Springer, Berlin, Heidelberg 2005: 21-31.

4. Fatu C, Puisoru M, Rotaru M, et al. Morphometric evaluation of the frontal sinus in relation to age. Ann Anat. 2006; 188(3): 275-280, doi: 10.1016/j.aanat.2005.11.012, indexed in Pubmed: 16711167.

5. Friedman $M$, Bliznikas D, Vidyasagar $R$, et al. Frontal sinus surgery 2004: update of clinical anatomy and surgical techniques. Operative Techniques Otolaryngology-Head Neck Surgery. 2004; 15(1): 23-31, doi: 10.1053/j. otot.2004.02.004.

6. Guerram A, Le Minor JM, Renger S, et al. Brief communication: the size of the human frontal sinuses in adults presenting complete persistence of the metopic suture. Am J Phys Anthropol. 2014; 154(4): 621-627, doi: 10.1002/ ajpa.22532, indexed in Pubmed: 24888448.

7. Kew J, Rees GL, Close D, et al. Multiplanar reconstructed computed tomography images improves depiction and understanding of the anatomy of the frontal sinus and recess. Am J Rhinol. 2002; 16(2): 119-123, indexed in Pubmed: 12030358.

8. Lee D, Brody R, Har-El G. Frontal sinus outflow anatomy. Am J Rhinol. 1997; 11(4): 283-285, doi: 10.2500/105065897781446720, indexed in Pubmed: 9292179.

9. Lee MK, Sakai O, Spiegel JH. CT measurement of the frontal sinus - gender differences and implications for frontal cranioplasty. J Craniomaxillofac Surg. 2010; 38(7): 494-500, doi: 10.1016/j.jcms.2010.02.001, indexed in Pubmed: 20335041.

10. McLaughlin RB, Rehl RM, Lanza DC. Clinically relevant frontal sinus anatomy and physiology. Otolaryngol Clin North Am. 2001; 34(1): 1-22, doi: 10.1016/s00306665(05)70291-7.

11. Tatlisumak E, Ovali GY, Asirdizer M, et al. CT study on morphometry of frontal sinus. Clin Anat. 2008; 21(4): 287-293, doi: 10.1002/ca.20617, indexed in Pubmed: 18428994. 